УДК 621.9

DOI: https://doi.org/10.26642/ten-2020-1(85)-60-65

В.С. Майборода, д.т.н., проф.

И.В. Слободянюк, к.т.н., доц.

Д.Ю. Джулий, к.т.н., доц.

КПИ имени Игоря Сикорского

А.И. Зелинко, магистр

Магдебургский университет имени Отто-фон-Герике

\title{
Магнитно-абразивная обработка плоских поверхностей головками на постоянных магнитах
}

\begin{abstract}
Исследованы особенности магнитно-абразивной обработки плоских поверхностей ферромагнитных деталей ториевыми магнитными головками, изготовленными с использованием высокомощных постоянных неодимовых магнитов. Изучено распределение магнитного поля вблизи рабочей поверхности магнитных головок типа щетка и полутор. Проведен ичкл исследований по влиянию формы рабочих поверхностей магнитных головок в виде: кольцевого выступа на периферии головки, с радиальными лучевыми выступами и группой радиально расположенных пирамидальных выступов высотой 2-3 мм на обеспечиваемую в результате магнитно-абразивной обработки шероховатость плоских ферромагнитных деталей. Показана возможность получения в результате магнитно-абразивной обработки ториевыми магнитными головками шероховатости поверхности с Ra < 0,05 мкм при исходной шероховатости на уровне $R a=1-1,25$ мкм. Установлено, что эффективный процесс магнитно-абразивной обработки будет реализовываться в том случае, когда отношение изменения шероховатости, достигаемое в прочессе обработки к исходной шероховатости будет превышать величину 0,85. Проанализировано влияние величины рабочего зазора, высоты формирующегося магнитноабразивного инструмента и величины магнитной индукции в зонах обработки на эффективность процесса. Рекомендовано использование магнитных головок типа щетка, у которых на рабочие ториевые поверхности нанесены выступы в виде группы пирамид высотой 2-3 мм. Для головок подобного типа эффективность обработки соответствует величине 0,89-0,91.

Ключевые слова: магнитно-абразивная обработка; плоские поверхности; эффективность; шероховатость; магнитные головки ториевого типа; неодимовые магниты.
\end{abstract}

Актуальность темы. При обеспечении финишной обработки как плоских поверхностей, так и поверхностей с малой кривизной важной задачей является разработка методов и устройств, которые достаточно мобильны и могут быть использованы на универсальном металлорежущем оборудовании. Одним из перспективных направлений при решении данной проблемы является применение метода магнитно-абразивной обработки (МАО), у которого для формирования магнитно-абразивного инструмента (МАИ) применяют сменные магнитные головки, изготовленные с использованием постоянных магнитов с высокой степенью намагниченности.

Анализ последних исследований и публикаций, на которые ссылается автор. Для обеспечения эффективного процесса МАО необходимо выполнение трех основных условий $[1,2]$ :

- обеспечение равномерного прижима элементов МАИ к обрабатываемым поверхностям;

- наличие достаточной и равномерно распределенной относительно обрабатываемых поверхностей тангенциальной составляющей скорости относительного движения элементов МАИ и обрабатываемой поверхности;

- способность МАИ к постоянному перемешиванию, восстановлению рабочей формы, нивелированию процессов, приводящих к выбрасыванию и вытеснению порошка из зон активной обработки.

При МАО плоских поверхностей реализация выполнения первого условия будет обеспечиваться за счет использования энергии магнитного поля магнитов, особенностей создания заданного градиента магнитной индукции в зоне обработки между обрабатываемой поверхностью и рабочей поверхностью магнитной головки, величиной зазора.

Реализация второго и третьего условий может быть связана с характером движения головки, видом градиента магнитной индукции в зоне обработки, конструкцией и формой рабочих поверхностей корпуса головки, которые принимают непосредственное участие в формировании МАИ и способствуют активному перемещению и перемешиванию частиц МАИ относительно обрабатываемых поверхностей [3-5].

Исследования, выполненные в данной области показали перспективность применения постоянных магнитов для финишной обработки методом МАО [6-9]. Общим недостатком известных работ является отсутствие конкретной информации о технологическом процессе и рекомендаций по использованию предлагаемых схем и конструкций. 
Целью работы было разработать реальные конструкции магнитных головок торцевого типа и выполнить оценку их работоспособности.

В качестве базовых элементов рабочих головок рассматривали возможности использования высокомощных неодимовых магнитов в виде цилиндра диаметром 40 мм и высотой 20 мм и двух кольцевых цилиндров с аналогичной высотой, вставленных друг в друга так, чтобы они были ориентированы к рабочей поверхности противоположными полюсами. Характерный вид расположения магнитно-абразивного порошка на рабочей поверхности головок торцевого типа представлен на рисунке 1. Условно головки были названы по внешнему виду формируемого на рабочей поверхности МАИ как полутор и щетка.

На первом этапе исследовано изменение величины магнитной индукции $-B$ в зависимости от расстояния от рабочей поверхности головок. Полученные результаты по максимальной величине магнитной индукции приведены на рисунке 2. Показано, что с увеличением расстояния от рабочей поверхности величина магнитной индукции снижается по зависимостям близким к линейным. Причем скорость уменьшения величины $B$ для головки типа щетка составляет 0,0228 Тл/мм, а для полутора 0,0335 Тл/мм. Подобная разница в характере снижения магнитной индукции связана как со степенью намагниченности магнитов, так и с особенностями распределения силовых магнитных линий вблизи торцевой поверхности головок.

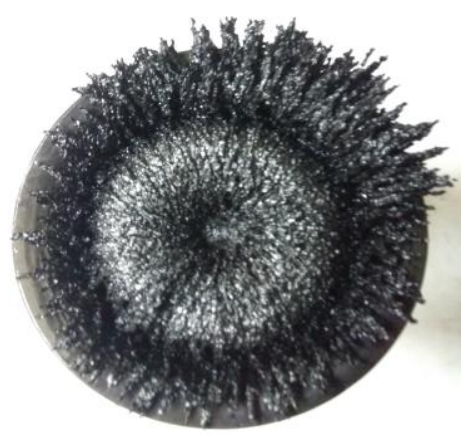

а) полутор

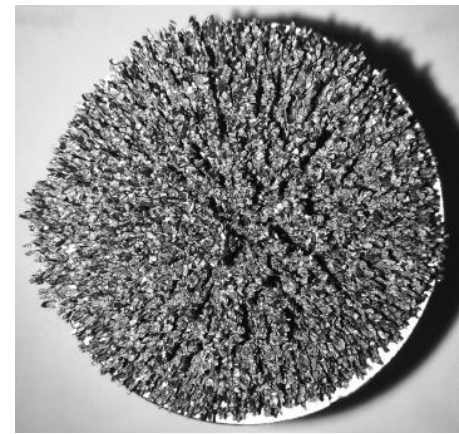

б) щететка

Рис. 1. Расположение порочка на рабочих поверхностях рабочих головок после цикла МАО ферромагнитных деталей

На втором этапе проведены испытания головок с гладкой рабочей поверхностью с МАИ вида полутор и щетка при рабочих зазорах (высоте МАИ) 2 и 3 мм. Оценку эффективности процесса МАО выполняли по величине абсолютного изменения параметра шероховатости $-\Delta R a=R a_{\text {исх }}-R a_{\text {кон }}$ и относительного изменения параметра шероховатости $-\Delta R a / R a_{\text {исх }}$.

Испытания рабочих головок выполняли при частоте вращения головок 900 об/мин, величине подачи 10 мм/мин. В качестве магнитно-абразивного порошка использовали Ферромап с размером частиц 630/400 мкм. В качестве обрабатываемого материала использовали предварительно фрезерованную торцевой фрезой деталь из стали 45 с $R a=0,9-1$ мкм.

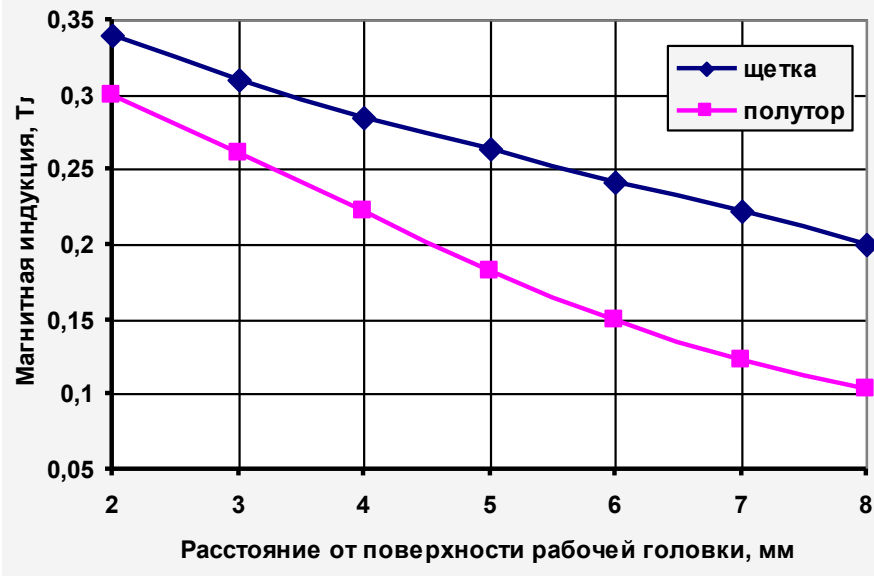

Рис. 2. Изменение величины магнитной индукичи в зависимости от расстояния от рабочей поверхности головок 
Отметим, что данная шероховатость измерялась в направлении, совпадающем с направлением подачи при фрезеровании. Полученные результаты представлены в таблице 1.

Изменение параметра Rа после МАО головками с МАИ различной высоты

Таблица 1

и разной магнитной индукиией в рабочем зазоре

\begin{tabular}{|c|c|c|c|c|c|}
\hline $\begin{array}{c}\text { Тип } \\
\text { МАИ }\end{array}$ & $\begin{array}{c}\text { Высота МАИ, } \\
\text { мм }\end{array}$ & $\begin{array}{c}\text { Магнитная индукция в } \\
\text { рабочем зазоре, Тл }\end{array}$ & $R a_{\text {исх, мкм }}$ & $\Delta R \mathrm{a}$, мкм & $\Delta R a / R a_{\text {исх }}$ \\
\hline \multirow{2}{*}{ Полутор } & 3 & 0,26 & 0,95 & 0,17 & 0,18 \\
\hline & 2 & 0,3 & 0,9 & 0,16 & 0,18 \\
\hline \multirow{2}{*}{ Щетка } & 3 & 0,305 & 1 & 0 & 0 \\
\hline & 2 & 0,34 & 0,99 & 0,02 & 0,02 \\
\hline
\end{tabular}

Наблюдения за особенностями поведения МАИ при реальной обработке показали, что не выполняется второе основное условие для обеспечения эффективного МАО - отсутствует достаточное относительное перемещение МАИ и обрабатываемой поверхности. Зафиксировано преимущественное перемещение МАИ по поверхности головок, что приводило в основном к обработке ее рабочей поверхности и нагреву. Данные эффекты являются недопустимыми. Для обеспечения выполнения второго основного условия эффективного МАО предложено использовать различные формы рабочей поверхности магнитных головок - с кольцевым выступом на периферии головки, с радиальными лучевыми выступами и группой радиально расположенных пирамидальных выступов высотой 2-3 мм (рис. 2).

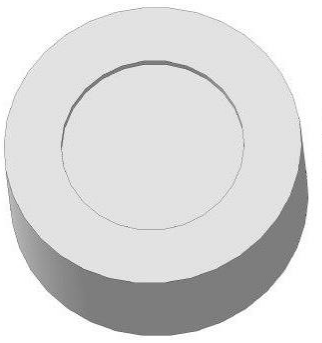

Тип 1

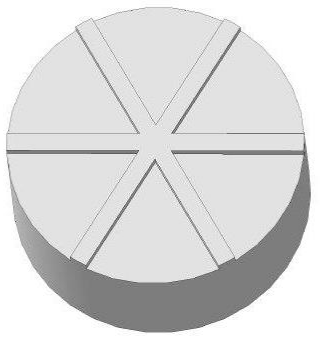

Тип 2

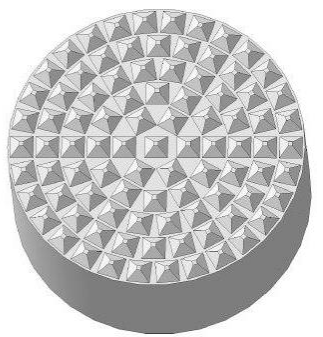

Тип 3

Рис. 3. Конструкциии рабочих поверхностей магнитньх головок

Результаты экспериментальных испытаний представлены в таблице 2. Показано, что уже при наличии кольцевого выступа на периферии рабочей поверхности головки (тип 1) проявляется резкий рост эффективности процесса МАО за счет ограничения зоны активной обработки и создания заклинивающих зон при формировании МАИ. Причем для головки, в которой используется два кольцевых магнита (полутор), эффект заклинивания более ярко выражен. Для головки с МАИ в виде щетки наилучшие результаты получены при рабочем зазоре 4 мм. Увеличение и уменьшение рабочего зазора приводит к некоторому снижению эффективности МАО. Использование рабочих поверхностей второго и третьего типов на головках, которые формируют МАИ вида полутор, привело к негативным результатам, так как сформированные выступы привели к нарушению сплошности, сформированному по кольцу МАИ между противоположными полюсами магнитов, и невыполнению третьего условия.

Таблииа 2

Изменение параметра Ra после МАО различными магнитными головками

\begin{tabular}{|c|c|c|c|c|c|}
\hline $\begin{array}{c}\text { Тип рабочей } \\
\text { поверхности головок }\end{array}$ & ТиП МАИ & $\begin{array}{c}\text { Высота МАИ, } \\
\text { мм }\end{array}$ & $R a_{\text {исх, мкм }}$ & $\Delta R a$, мкм & $\Delta R a / R a_{\text {исх }}$ \\
\hline \multirow{4}{*}{1} & \multirow{2}{*}{ Полутор } & 4 & 0,89 & 0,75 & 0,84 \\
\hline & & 3 & 0,95 & 0,85 & 0,89 \\
\hline & \multirow{2}{*}{ Щетка } & 4 & 0,83 & 0,74 & 0,89 \\
\hline & & 3 & 0,72 & 0,57 & 0,79 \\
\hline \multirow{2}{*}{2} & Полутор & 4 & 1,24 & 0,62 & 0,5 \\
\hline & Щетка & 4 & 1,29 & 1,1 & 0,85 \\
\hline \multirow{3}{*}{3} & Полутор & 4 & 0,67 & 0,19 & 0,28 \\
\hline & \multirow{2}{*}{ Щетка } & \multirow{2}{*}{4} & 1,57 & 1,42 & 0,9 \\
\hline & & & 0,77 & 0,7 & 0,91 \\
\hline
\end{tabular}


Полученные результаты показали, что перспективным направлением в создании конструкций головок с МАИ вида щетка будут те, у которых на рабочую поверхность нанесены выступы различной формы. При этом такие головки будут эффективны в случае когда $\Delta R a / R a_{\text {исх }}>0,85$. Нанесенные на рабочую поверхность выступы обеспечивают выполнение второго и третьего условия для обеспечения эффективного процесса МАО.

На третьем этапе исследований анализировали влияние величины магнитной индукции в рабочем зазоре и высоты МАИ на эффективность МАО. Для этого в качестве базовой конструкции головки был выбран полутор с рабочей поверхностью первого типа. Высота кольцевого выступа, расположенного на периферии головки, варьировалась в диапазоне от 0 до 6 мм, величина зазора между обрабатываемой поверхностью и поверхностью выступа составляла 1, 2 и 3 мм, что позволило менять величину рабочего зазора и высоту МАИ от 2 до 9 мм и соответственно величину магнитной индукции в зоне обработки от 0,1 до 0,3 Тл. Дополнительно контролировали величину $\mathrm{Ra}$ в перпендикулярном направлении направлении перпендикулярном вектору подачи торцевой фрезы.

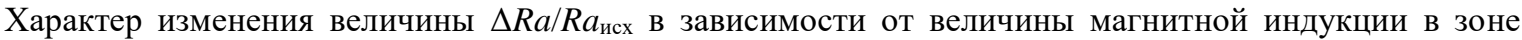
обработки представлен на рисунке 4.

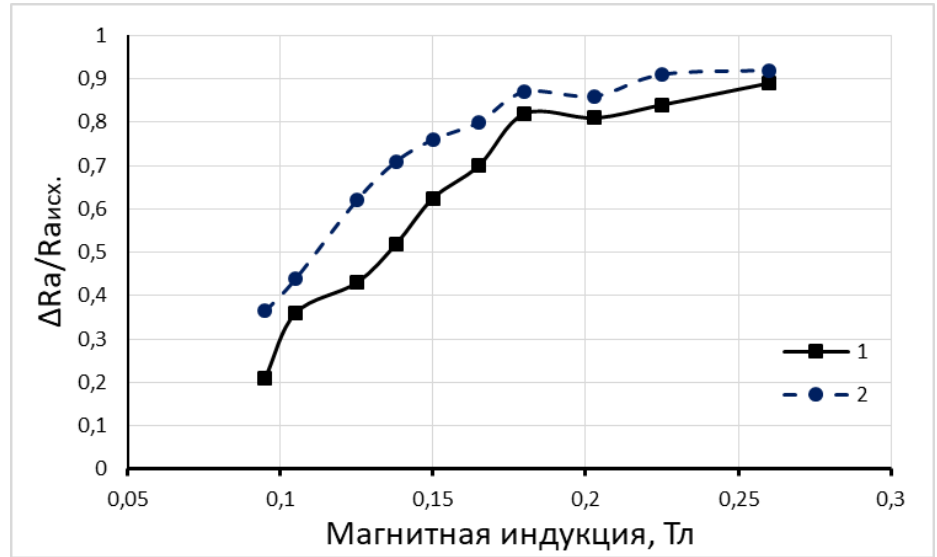

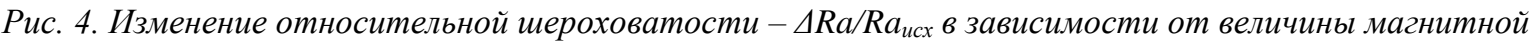
индукции в рабочих зазорах. 1 - параметр $\Delta R a / R a_{u с x}$, полученный при измерениях в направлении, совпадающем с подачей при фрезеровании, 2 - параметр $\Delta R a / R a_{u с x}$, полученный при измерениях 8 направлении перпендикулярном вектору подачи ториевой фрезы

Анализ полученных результатов показал, что при обработке плоских поверхностей из ферромагнитных материалов величина магнитной индукции в зонах обработки должна быть не менее 0,18 Тл в рабочих зазорах, свободных от порошка. При этом целесообразно использование рабочих зазоров менее 5 мм. Следует отметить, что нижняя граница величины рабочего зазора будет определяться размером частиц магнитно-абразивных порошков. Так для порошков, которые были использованы при проведении выше описанных исследований, эта граница составляет 2-2,5 мм. Меньшие зазоры при МАО приводят к ухудшению шероховатости поверхности и ее шаржированию (рис. 5). Данная величина связана с разметом квазистабильных представительских объемов, из которых формируется МАИ [2]. При использовании более мелких порошковых материалов величина рабочего зазора может уменьшатся до $1-1,5$ мм.

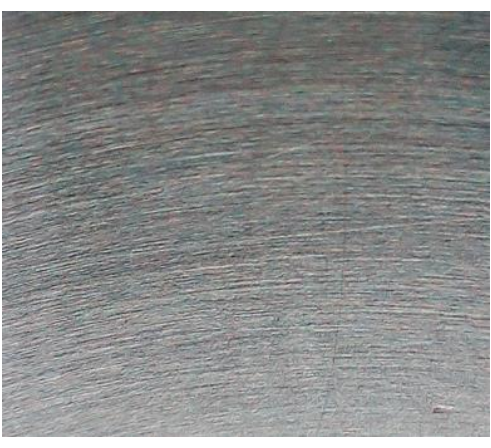

a)

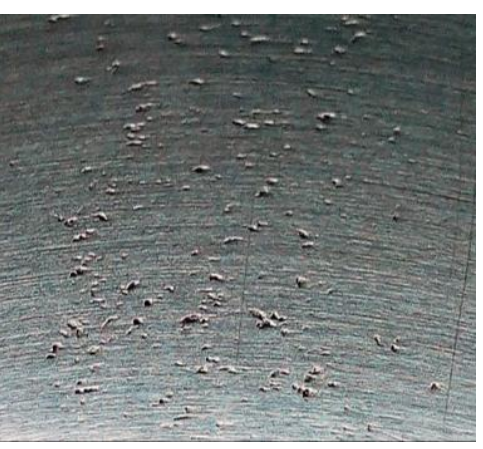

б)

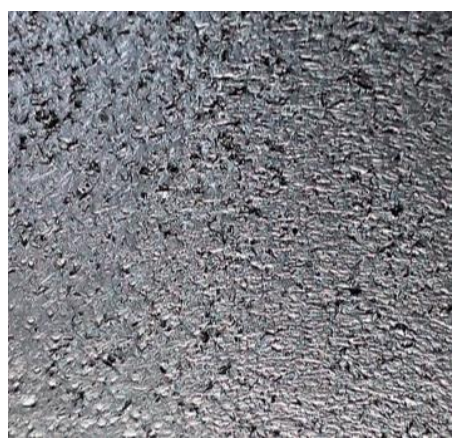

6)

Рис. 5. Фотографии поверхностей образцов из стали 45 после МАО (x4) порошком Ферромап (630/400 мкм) с рабочим зазором: а) - 3,5 мм, б) - 2,5 мм, в) - 1,5 мм 
На четвертом этапе исследований анализировали влияние второго и третьего типов рабочих головок с МАИ высотой 4 и 5 мм в виде щетки при МАО образцов из стали 45. Полученные результаты сравнивали с обработкой головками, формирующими МАИ в виде полутора. Экспериментальные данные представлены в таблице 3.

Анализ полученных результатов показал, что выступы, нанесенные на рабочую поверхность магнитных головок, что формируют МАИ вида щетка, обеспечивают не только выполнение второго и третьего условий эффективного процесса МАО, а и позволяют после фрезерования и последующего МАО формировать шероховатость поверхности на уровне $0,06-0,15$ мкм при исходной шероховатости $R a=0,7-1,6$ мкм. Причем чем ниже исходная шероховатость, тем меньше формируется шероховатость после МАО. В случае, когда исходная шероховатость не превышала $R a=0,7$ мкм, в процессе МАО практически полностью удалялась волнистость поверхности, формируемая на стадии торцевого фрезерования.

Таблий 3

Изменение параметра Rа после МАО различными магнитными головками

\begin{tabular}{|c|c|c|c|c|c|}
\hline $\begin{array}{c}\text { Тип рабочей } \\
\text { поверхности головок }\end{array}$ & Тип МАИ & $\begin{array}{c}\text { Высота } \\
\text { МАИ, мм }\end{array}$ & $\boldsymbol{R} \boldsymbol{a}_{\text {исх, мкм }}$ & $\Delta R a$, мкм & $\Delta R a / R a_{\text {исх }}$ \\
\hline \multirow[t]{4}{*}{ 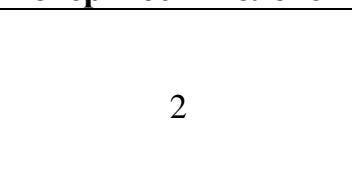 } & \multirow{2}{*}{ Полутор } & 5 & 0,92 & 0,34 & 0,37 \\
\hline & & 4 & 1,24 & 0,62 & 0,5 \\
\hline & \multirow{2}{*}{ Щетка } & 5 & 1,29 & 1,1 & 0,85 \\
\hline & & 4 & 1,29 & 1,1 & 0,85 \\
\hline \multirow{4}{*}{3} & \multirow{2}{*}{ Полутор } & 5 & 0,77 & 0,28 & 0,36 \\
\hline & & 4 & 0,67 & 0,18 & 0,27 \\
\hline & \multirow{2}{*}{ Щетка } & 5 & 1,55 & 1,4 & 0,9 \\
\hline & & 4 & 1,57 & 1,42 & 0,9 \\
\hline
\end{tabular}

Показано, что применение магнитных головок третьего типа является предпочтительным, так как обеспечивает наивысшую эффективность, которая проявляется в значениях $\Delta R a / R a_{\text {исх }} \geq 0,9$. Полученные результаты практически идентичны как при анализе изменения параметра $\mathrm{Ra}$ полученных при измерениях в направлении, совпадающем с подачей при фрезеровании, так и при измерениях в перпендикулярном направлении вектору подачи торцевой фрезы при подготовке поверхностей для МАО.

Важно отметить, что необходимо проведение дополнительного цикла исследований по влиянию как формы выступов, так и их плотности расположения на рабочей поверхности магнитных головок на эффективность процесса МАО.

Дополнительно было исследовано влияние частоты вращения головок в диапазоне 510-1400 об/мин с рабочей поверхностью третьего типа. Установлено, что в указанном диапазоне частот вращения головок имеет место незначительное увеличение величины $\Delta R a / R a_{\text {исх }}$ от 0,9 до 0,94 с возрастанием частоты вращения. При этом устойчиво обеспечивается шероховатость обработанных методом МАО ферромагнитных плоских поверхностей на уровне $R a=0,03-0,07$ мкм.

Выводы. Выполненные исследования различных магнитных головок торцевого типа на высокомощных постоянных магнитах показали, что на рабочей торцевой поверхности головок целесообразно нанесение выступов различной формы, которые обеспечивают проведение МАО ферромагнитных плоских поверхностей с высокой эффективностью, которую характеризовали величиной относительного изменения параметра шероховатости $-\Delta R a / R a_{u c x}>0,85$. Наилучшие результаты получены при величине магнитных зазоров меньше 5 мм на торцевых головках, которые в процессе МАИ формируют магнитно-абразивный инструмент в виде щетки с рабочими поверхностями, на которые нанесены выступы в виде группы пирамид. Показано, что при исходной шероховатости поверхности после торцевого фрезерования с $\mathrm{Ra}=0,7-1,5$ мкм возможно получение шероховатости поверхности после MAO с $R a<0,05$ мкм с отсутствием волнистости, формируемой на этапе фрезерования. Установлено, что при частоте вращения торцевых магнитных головок в диапазоне 510-1400 об/мин имеет место незначительный рост величины $\Delta R a / R a_{u c x}$ от 0,9 до 0,94 с возрастанием частоты вращения, а шероховатость обработанных поверхностей составляет $R a=0,03-0,07$ мкм.

\section{Список использованной литературы:}

1. Майборода В.С. Дослідження властивостей магнітно-абразивного інструменту, сформованого 3 двох фракційних сумішей порошків при магнітно-абразивній обробці у великих магнітних щілинах / B.C. Майборода // Технологічні системи. - 2007. - № 1 (37). - С. 40-55.

2. Майборода B.C. Магнитно-абразивная обработка деталей сложной формы / B.C. Майборода, И.В. Слободянюк, Д.Ю. Джулий. - Житомир : ПП «Рута», 2017. - 272 с.

3. Хомич Н.С. Магнитно-абразивная обработка изделий / Н.С. Хомич. - Минск : БНТУ, 2006. -218 с. 
4. Лепший А.П. Магнитно-абразивная обработка крупногабаритных плоских поверхностей : дис. ... канд. тех. наук : 05.03.01, 05.02.08 / А.П. Лепший. - Минск, 1992. - 135 с.

5. Вплив режимів магнітно-абразивного оброблення на шорсткість плоских поверхонь / B.C. Майборода, Д.Ю. Дюулій, І.В. Слободянюк, Ю.В. Коиун // Тези доповідей VIII міжнародної науково-практичної конференції «Комплексне забезпечення якості технологічних процесів і систем». - Чернігів, 2018. - С. 139-141.

6. Барон Ю.M. Магнитно-абразивная и магнитная обработка изделий и режущих инструментов / Ю.М. Барон. - Л. : Машиностроение, Ленингр. отд-ние, 1986. - 176 с.

7. Harsh $K$. Magnetorheological nano-finishing of diamagnetic material using permanent magnets tool / K.Harsh, G.Vishwas // Precision Engineering. - 2018. - № 51. - C. 30-39.

8. Jain V.K. Chemo-mechanical magneto-rheological finishing (CMMRF) of silicon for microelectronics applications / V.K. Jain, P.Ranjan // CIRP Annals-Manufacturing Technology. - 2019. - № 59. - C. 323-238.

9. Wang Y.Q. Magnetorheological polishing using a permanent magnetic yoke withstraight air gap for ultra-smooth surface planarization / Y.Q. Wang, S.H. Yin // Precision Engineering. - 2014. - № 13. - C. 1-9.

10. Майборода В.С. Основи створення і використання порошкового магнітно-абразивного інструменту для фінішної обробки фасонних поверхонь : дис. ... д-ра техн. наук / В.С. Майборода. - Київ, 2001. - 404 с.

\section{References:}

1. Majboroda, V.S. (2007), «Doslidzhennja vlastyvostej magnitno-abrazyvnogo instrumentu, sformovanogo z dvoh frakcijnyh sumishej poroshkiv pry magnitno-abrazyvnij obrobci u velykyh magnitnyh shhilynah», Tehnologichni systemy, No. 1 (37), pp. 40-55

2. Maiboroda, V.S., Slobodyanyuk, I.V. and Dzhulii, D.Yu. (2017), Magnitno-abrazivnaya obrabotka detalei slozhnoi formy, Ruta, Zhitomir, 272 p.

3. Khomich, N.S. (2006), Magnitno-abrazivnaya obrabotka izdelii, BNTU, Minsk, 218 p.

4. Lepshii, A.P. (1992), «Magnitno-abrazivnaya obrabotka krupnogabaritnykh ploskikh poverkhnostei», Ph.D. Thesis of dissertation, 05.03.01, 05.02.08, Minsk, $135 \mathrm{p}$.

5. Majboroda, V.S., Dzhulij, D.Ju., Slobodjanjuk, I.V. and Kocun, Ju.V. (2018), "Vplyv rezhymiv magnitnoabrazyvnogo obroblennja na shorstkist' ploskyh poverhon'», Tezy dopovidej VIII mizhnarodnoi' naukovo-praktychnoi' konferencii' «Kompleksne zabezpechennja jakosti tehnologichnyh procesiv i system», Chernigiv, pp. 139-141.

6. Baron, Yu.M. (1986), Magnitno-abrazivnaya i magnitnaya obrabotka izdelii $i$ rezhushchikh instrumentov, Mashinostroenie, Leningr. otd-nie, L., 176 p.

7. Harsh, K. and Vishwas, G. (2018), «Magnetorheological nano-finishing of diamagnetic material using permanent magnets tool», Precision Engineering, No. 51, pp. 30-39.

8. Jain, V.K. and Ranjan, P. (2019), «Chemo-mechanical magneto-rheological finishing (CMMRF) of silicon for microelectronics applications», CIRP Annals-Manufacturing Technology, No. 59, pp. 323-238.

9. Wang, Y.Q. and Yin, S.H. (2014), «Magnetorheological polishing using a permanent magnetic yoke withstraight air gap for ultra-smooth surface planarization», Precision Engineering, No. 13, pp. 1-9.

10. Majboroda, V.S. (2001), «Osnovy stvorennja i vykorystannja poroshkovogo magnitno-abrazyvnogo instrumentu dlja finishnoi' obrobky fasonnyh poverhon'», D.Sc. Thesis of dissertation, Kyi'v, 404 p.

Майборода Виктор Станиславович - доктор технических наук, профессор Киевского политехнического института имени Игоря Сикорского.

Научные интересы:

- физика процессов резания;

- финишная обработка;

- реология порошковых сред в магнитном поле.

Слободянюк Иванна Валентиновна - кандидат технических наук, доцент Киевского политехнического института имени Игоря Сикорского.

Научные интересы:

- магнитно-абразивная обработка;

- реология порошковых сред в магнитном поле.

Джулий Дмитрий Юрьевич - кандидат технических наук, доцент Киевского политехнического института имени Игоря Сикорского.

Научные интересы:

- магнитно-абразивная обработка;

- упрочнение твердосплавного инструмента.

Зелинко Андрей Игоревич - магистр Магдебургского университета имени Отто-фон-Герике. Научные интересы:

- технология машиностроения;

- магнитно-абразивная обработка плоских деталей 